\title{
Communication Skills
}

\author{
"Dr. Mohd. Muzzaffar Hussain Khan, ${ }^{* *}$ Shaik. Liyakhath Ali. \\ *Dr.Mohd.Muzzaffar Hussain Khan, Assistant Professor, Dept. of Education and Training, Maulana Azad \\ National Urdu University, Gachibowli, Hyderabad-32, \\ ** Shaik. Liyakhath Ali, Lecturer in Biological Sciences, Govt. District Institute of Education \& Training, \\ Mettugadda,Mahabubnager,Telengana State,
}

\begin{abstract}
Communication skills are of paramount importance in the era of globalization. Communication is defined at the sum of all things a person does when he wants to create understanding in the mind of another. It involves a systematic and continuous process of telling, listening and understanding. Effective communication involves listening speaking and taking turns. An effective communicator exhibits effective interpersonal communication skills. Good communication is a leadership quality. All effective leaders communicate in their unique communication style, yet some similarities are noteworthy. As leadership is to inspire and impress the team members, words used in proper context would strengthen the leadership quality of a leader. In the art of communication the leader is a master. Leaders should have a willingness to listen to inputs with a cordial mind communication is crucial in building trust and an open environment. The manner in which one communicates with and leads a team may play an important part in motivating them to work hard. The main theme and intent of the present paper is to discuss how leadership qualities enhance through communication skills in terms of writing skills, non-linguistic skills and Music as means of verbal and non-verbal communication. The paper ultimately concludes how communication skills can be developed in children at schools by conducting elocution, essay writing,symposia,seminars, conferences, fine arts such as drawing,sketching,painting and singing etc.,
\end{abstract}

Keywords: Communication, linguistic, gestures, soft skill, genuine.

\section{Introduction}

Communication skills are of paramount importance in the era of globalization. Communication being a broader concept is understood and defined in several ways by different people from different walks of life according to their experience and needs. Communication is defined as the sum of all things a person does when he wants to create understanding in the mind of another. It involves a systematic and continuous process of telling, listening and understanding. Effective communication involves listening speaking and taking turns. An effective communicator exhibits effective interpersonal communication skills.

We engage in interpersonal communication skills because we need to express and receive interpersonal needs. William Shultz has identified three needs inclusion, control and affection.

a. Inclusion in the need to establish identity with others.

b. Control is the need to exercise leadership and prove one's abilities.

c. Affection is the need to develop relationships with people. Groups are an excellent way to make friends and establish relationship.

Good communication is a leadership quality. All effective leaders communicate in their unique communication style, yet some similarities are noteworthy. As leadership is to inspire and impress the team members, words used in proper context would strengthen the leadership quality of a leader.

In the art of communication the leader is a master. Leaders should have a willingness to listen to inputs with a cordial mind communication is crucial in building trust and an open environment. The manner in which one communicates with and leads a team may play an important part in motivating them to work hard.

To maintain interpersonal relations in an organization the communication may flow upward, downward and sideways.

\section{Upward Communication:}

Communication flows upwards in an organization in both structured and unstructured manner. The most common forms of upward communication are focus groups, reports like progress report, periodic reports, periodic meetings investigation reports, suggestion boxes etc; These help in healthy channels of the participants in decision-making to attain a broader perspective on challenges and realities and to extend their own abilities to problem-solvers and potential leaders.

\section{Downward Communication:}

In downward communication, information passes from top to bottom. Superiors communicate with subordinates, which is directive in nature. Downward communication includes verbal directives (orders, commands, and comments) memos, policies, procedures training materials, assignments, performance, evaluation etc. 


\section{Lateral Communication:}

Lateral communication includes communication between the subordinates of same cadre, i.e. communication between colleagues or co-workers. Lateral communication is very helpful to interlink activities of different branches to build an inclusive team spirit and to promote intergroup information-sharing and problem-solving. It avoids the small delays caused by download communication.

\section{Writing Skills:}

Writing is one of the most common ways of communicating with others. It is a complex activity. It involves many sub-skills like writing legibly, spelling correctly, using good expressions, constructive grammatical sentences and putting them together. Developing ideas knot paragraphs, arranging the arguments logically and using different formats (letters, reports, essays and so on).A good - writer has the mastery of all these sub-skills.

\section{Communication on the Web:}

Internet is used for several things. There are sites which allow students to learn something, test their knowledge and prepare for some examinations. A web-page is a page that exists on the internet and can be visited by several users. Though web pages the users of the internet communicate with a wider range of people. Unlike printed pages in books, magazines and news-papers, web-pages are interactive. They do not just provide information. They allow the interaction with the person who created the web-page.

\section{Seminars and Conferences:}

Traditionally seminars and conferences are a part of academic routine. A seminar is a discussion group consisting of a fewer number of participants and focuses on the original research or advanced study. Usually a seminar is focussed on a specific theme. A conference is like a seminar but the number of participants is more and the coverage of the subject is also broader. Various aspects of the theme of the conference are discussed on the same time. Parallel sessions are held in a conference. The discussions in a conference usually end up on a central theme of the conference.

\section{Conference skills:}

Conference skills refer to skills of speaking in public like participation in discussion groups like seminars, conferences and symposia. Speaking in public, speaking to a person, involves effective linguistic and non-linguistic skills.

\section{Linguistic skills:}

Linguistic skills refer to skills in using the language effectively in any communication. The language used for communication depends mainly on i) the topic of communication ii) the relationship between the participants involved in the communication iii) the medium of communication iv) the context/situation and $\mathrm{v}$ ) the purpose.

\section{Medium of Communication:}

The medium of communication may be telephone, radio, TV, paper, face-to-face, public addressing system, and internet and so on. The medium we use in a particular communication act influences the way we use the language. The context in which the communication is taking place also influences the language we use in the situation.

\section{Non-linguistic skills:}

Communication through feelings, emotions, attitudes etc. are inclusive of non-linguistic skills. A facial expression such as smile indicates friendliness and it enhances good relationship with others. It fosters goodwill in others. Smiling is a genuine gesture that shows happiness. Posture plays a very important role in nonlinguistic communication. Eyes play a very important role in communication. It is generally understood that eyes reveal one's nature/character. A confident or honest person has a direct eye contact with others. Appearance is also a very important factor in effective communication .It creates an impression on the listener. The appearance may cause the success or otherwise of the communication.

\section{Music as a Communication skill:}

Since time immemorial music has enchanted mankind. Recent studies have shown that incorporating music in learning can help in increasing languages skills in children. Learning to play a musical instrument may help children to develop their abilities through music. Study at Stanford University has shown that mastering a musical instrument improves the ability to process parts of the spoken language. Music in the form of rhymes and songs enables children and adults both to memorize and learn large units of language matter, mathematics tables, days of a week, months of a year etc.

Topics such as Culture, society, Nationality and National integration etc. can be taught and inculcated in the young generation by music in the form of songs, folklore, national anthem and patriotic songs etc. Music as means of verbal and non-verbal communication helps the performer to express themselves in their own way discover, explore and identify the personal form and style of expression, It enables one develop one's skills in their use of various tools, instincts and other art material in the process of discovery and exploration. Music as a means of expression is a most acceptable soft - skill. 
According to the renowned musician Pandit Shiva Kumar "My music connects to the listeners soul to soul and gives the feeling of existence of the divine power."

Talat Aziz the Ghazal singer quotes "The sound of classical music is a divine experience. As I transcend the language of music along with the audience, Iam in a state of trance myself."

Gutsav Mahler "If a composer could say what he had to say in words he would not bother trying to say it in music."

Topics such as culture, society, nationality, national integration etc. can be taught and inculcated in the young generation by music in the form of songs, folklore, national anthem, patriotic songs etc.

\section{Conclusion}

Communication skills can be developed in children and in adults at schools and in institutions by conducting speeches, elocution, essay writing, symposia, seminars, conferences, fine arts such as drawing, sketching, painting and singing etc.

\section{Bibliography}

[1]. Personality development and communicative English,Dr.B.V. Pattabhi Ram,Dr.Ravikanth Rao,Dr. M.Hariprasad and Prof.V.Prakasam,Neelkamal Publications Pvt, Ltd.Edutracks, August, 2009, Vol B.No, 12

[2]. Essentials of Educational Psychology by J.C Agarwal-Vikas Publications.

[3]. Educational Psychology by S.S. Mathur - Vinod Pustak Mandir. 